cause di meningite e otite media. I fluorochinoloni rappresentano una delle opzioni terapeutiche per il trattamento di queste infezioni. Ad eccezione di alcuni paesi asiatici, la resistenza ad alto livello a questi antibiotici è molto rara e in Italia è presente in circa l'1\% degli isolati clinici.

Metodi. Nel marzo 2005, presso il nostro laboratorio è stato isolato un ceppo di S. pneumoniae ottenuto dal broncolavaggio alveolare di un paziente di 72 anni ricoverato presso il reparto di Terapia Intensiva per insufficienza respiratoria acuta. Il paziente era in trattamento ambulatoriale con levofloxacina (500 mg bid). Identificazione e antibiogramma sono stati effettuati col sistema Phoenix (Becton Dickinson, Diagnostics Systems, Sparks, MD). L'isolato risultava resistente a penicillina $\mathrm{G}$ (MIC, $>2 \mathrm{mg} / \mathrm{L}$ ), eritromicina (MIC, $>4 \mathrm{mg} / \mathrm{L}$ ), clindamicina (MIC, $>1 \mathrm{mg} / \mathrm{L}$ ), levofloxacina $(\mathrm{MIC},>4 \mathrm{mg} / \mathrm{L}$ ) e moxifloxacina (MIC, >2 mg/L) Telitromicina e piperacillina/tazobactam risultavano attivi (MIC, $\leq 0.006 \mathrm{mg} / \mathrm{L}$ e $1 \mathrm{mg} / \mathrm{L}$, rispettivamente). Il DNA batterico è stato amplificato per confermare l'identificazione biochimica utilizzando primers specifici per il gene della pneumolisina. I geni per la DNA girasi (geni gyrA e gyrB) e la Topoisomerasi IV (geni $\operatorname{parC}$ e parE) sono stati amplificati mediante PCR. Le mutazioni di tali geni sono state analizzate mediante sequenziamento.

Risultati. L'amplificazione genica ha confermato l'identificazione biochimica. Il sequenziamento genico ha evidenziato la presenza di mutazioni nei geni gyrA, parC e parE con sostituzione Ser84 $\rightarrow$ Phe a livello del gene gyrA, $\mathrm{Ser} 79 \rightarrow$ Phe e Lys $137 \rightarrow$ Asn in parC e Ile $459 \rightarrow$ Val in parE. La terapia è stata quindi modificata con l'aggiunta di piperacillina/tazobactam $(2.25 \mathrm{~g}$ tid) con completa risoluzione della sintomatologia clinica.

Conclusioni. L'isolamento di S. pneumoniae con caratteristiche di resistenza multipla agli antibiotici è un dato preoccupante che indica l'emergere di nuove resistenze e sottolinea la necessità di un costante monitoraggio al fine di prevenire la diffusione di cloni epidemici di difficile eradicazione.

\section{RESISTENZA AD ALTO LIVELLO \\ AI FLUOROCHINOLONI IN UN ISOLATO CILINICO DI STREPTOCOCCUS PNEUMONIAE}

Brigante G., Bettaccini A., Luzzaro F., Endimiani A., Pini B., Toniolo A..

Laboratorio di Microbiologia e Virologia, Ospedale di Circolo di Varese e Università degli Studi dell'Insubria

Introduzione. Streptococcus pneumoniae è la principale causa di polmonite comunitaria e una delle più importanti 